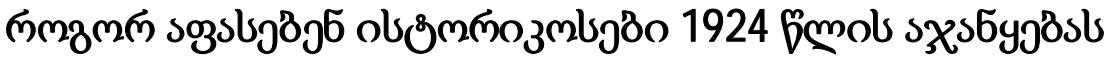

\author{
उmß̊os \\ ubo3 №6 bszsmm bzmms, f.ojms \\ https://doi .org/10.52340/idw.2021.501
}

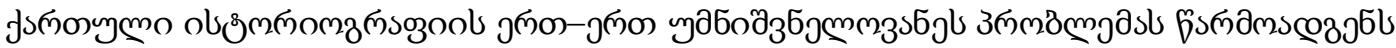

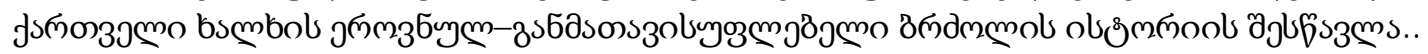

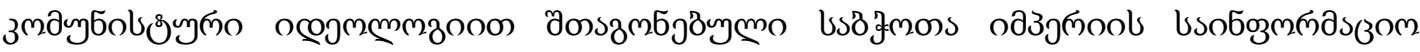

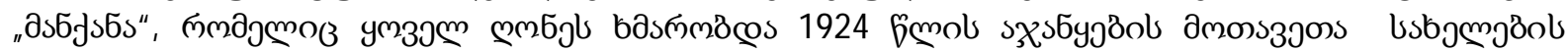

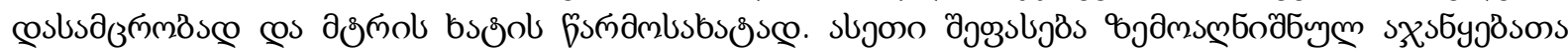

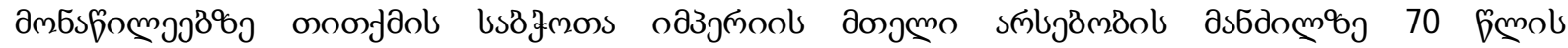

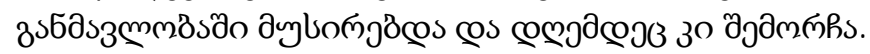

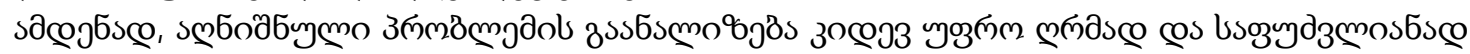

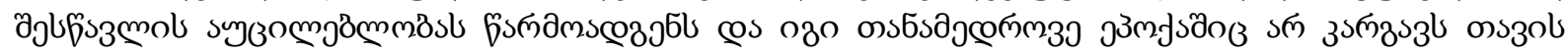
słơysmmßsts.
\end{abstract}

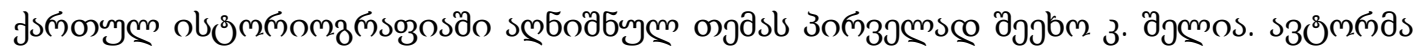

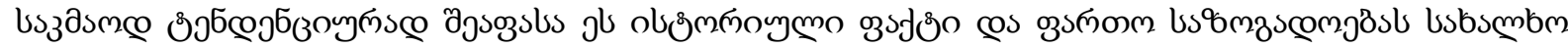

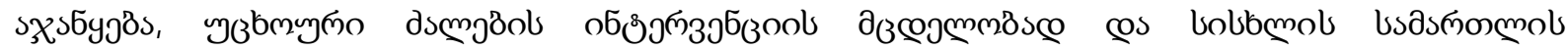

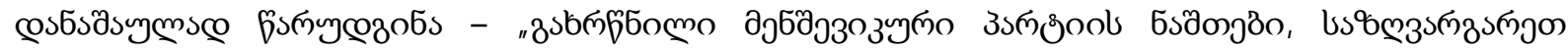

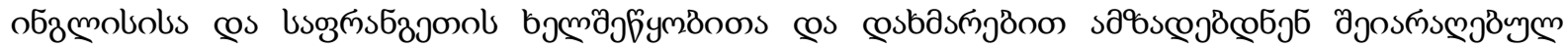

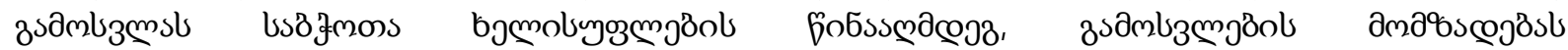

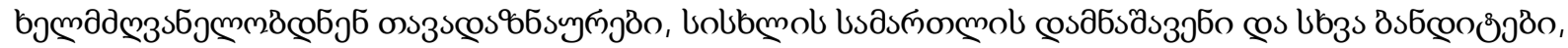

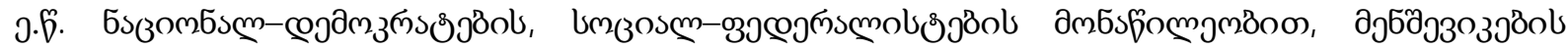

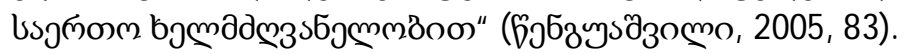

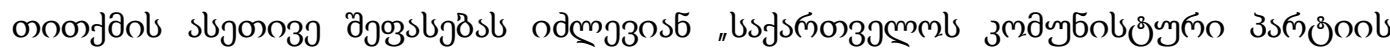

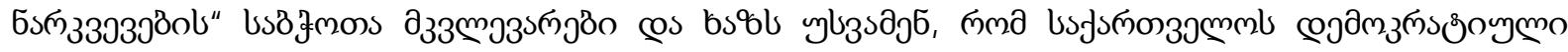

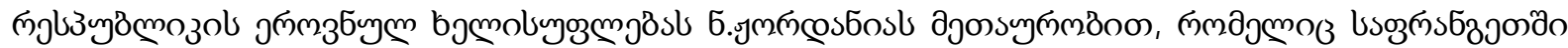

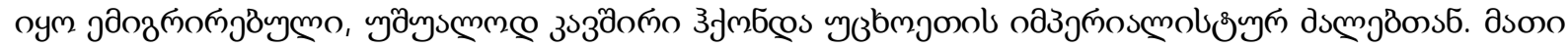

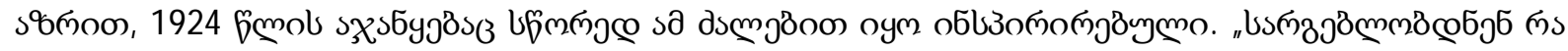

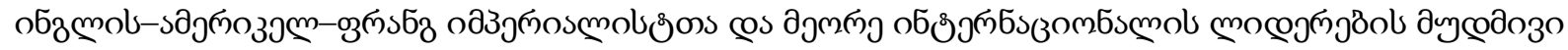

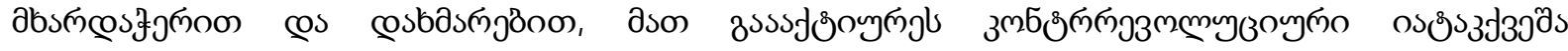

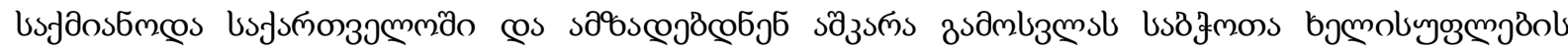

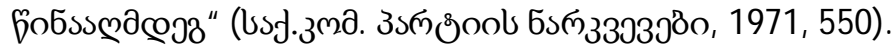

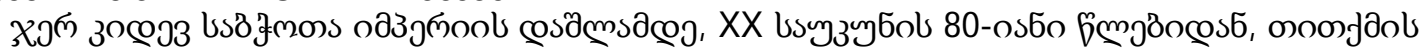

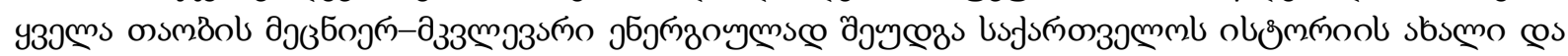

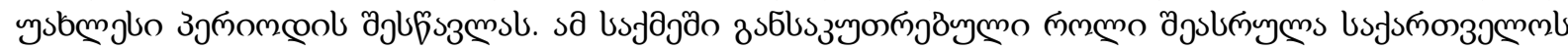

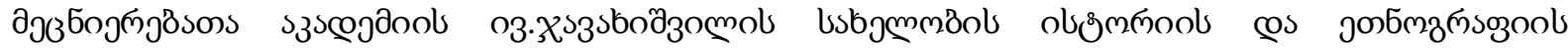

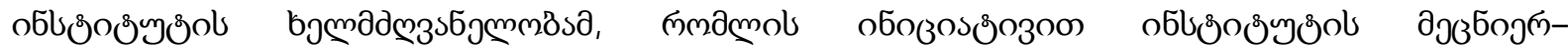

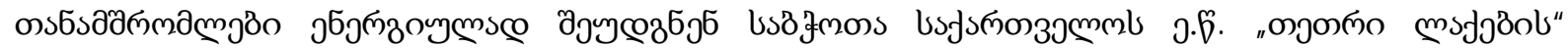

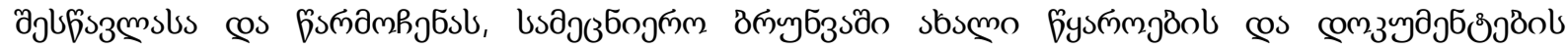

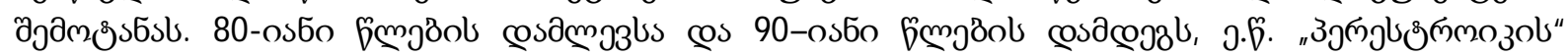

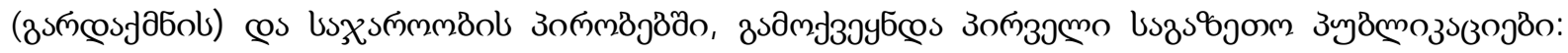

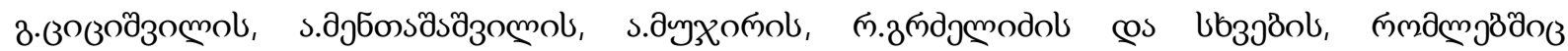




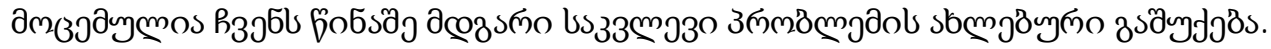

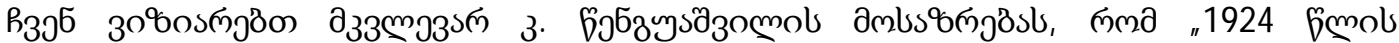

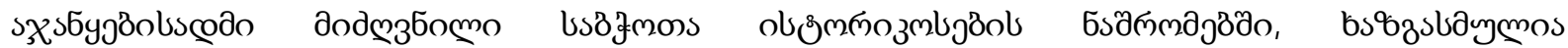

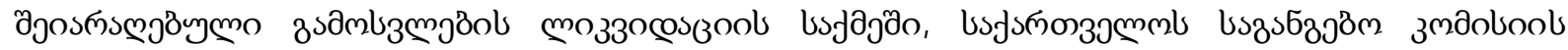

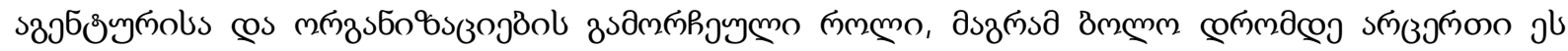

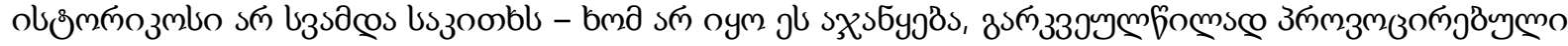

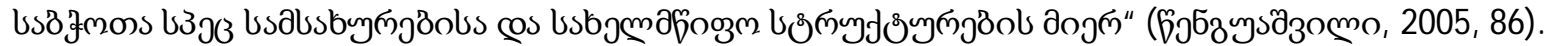

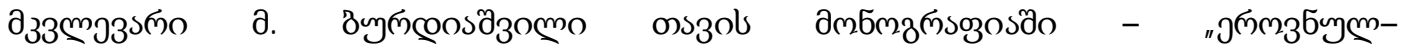

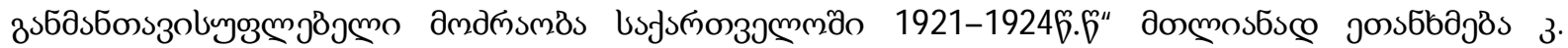

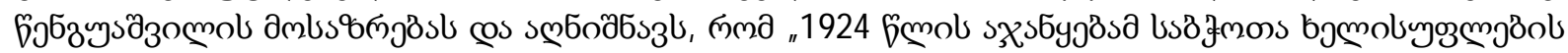

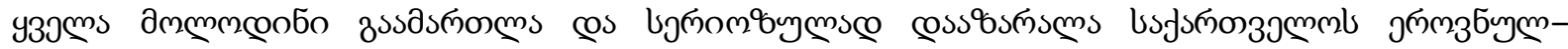

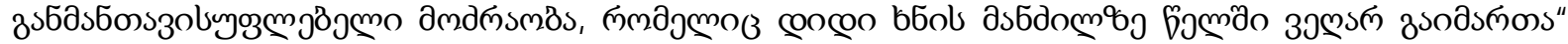

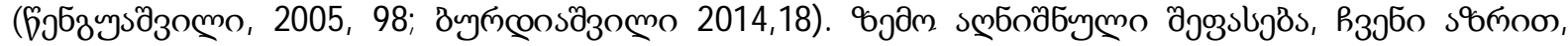

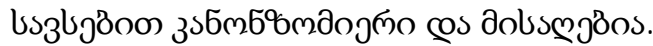

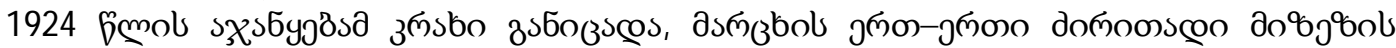

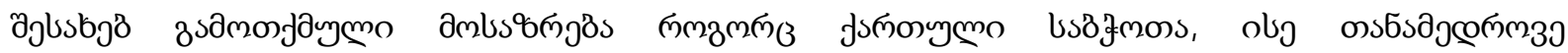

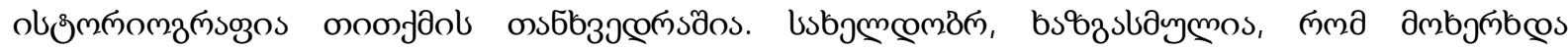

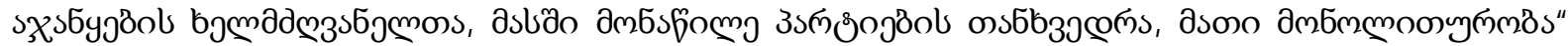

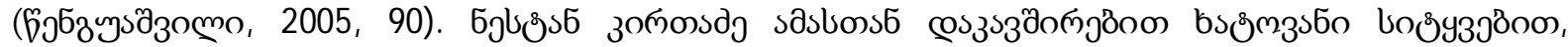

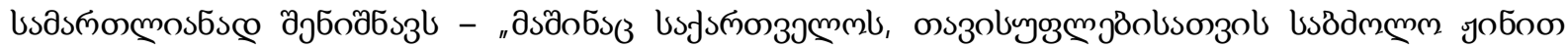

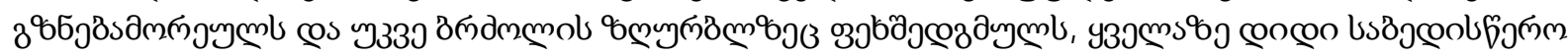

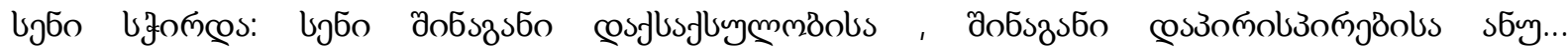

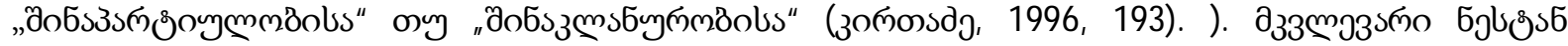

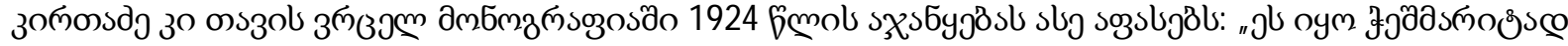

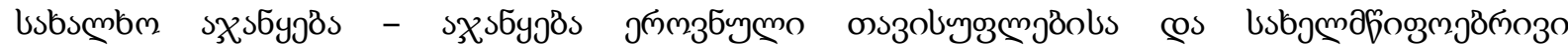

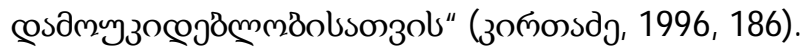

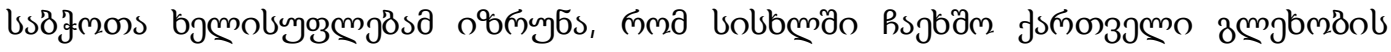

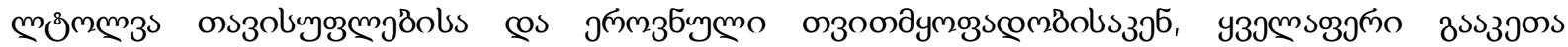

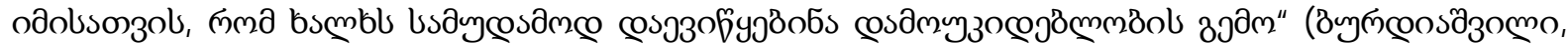
2014,20).

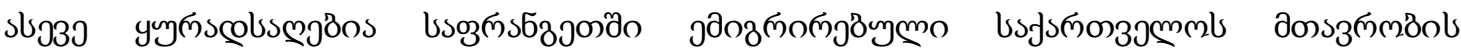

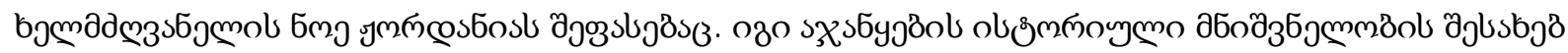

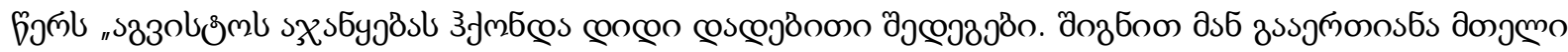

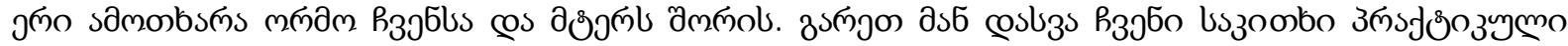

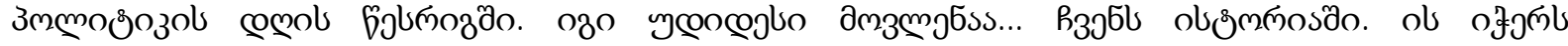

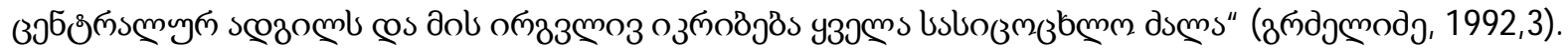

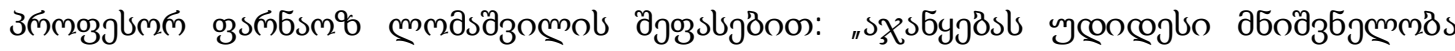

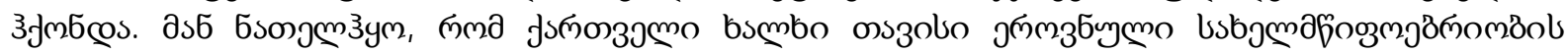

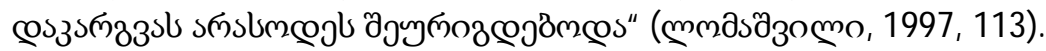

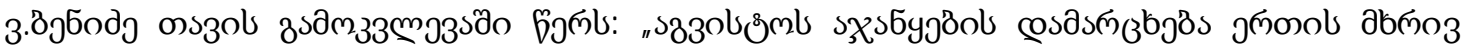

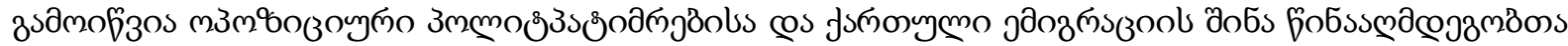

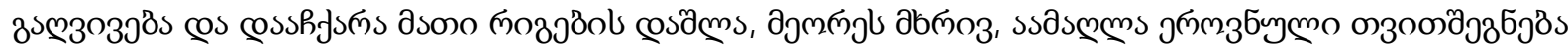

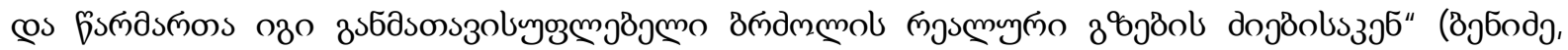
1991,32).

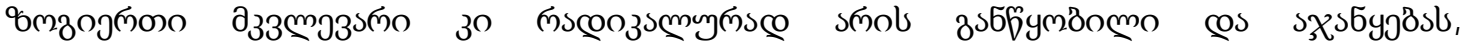

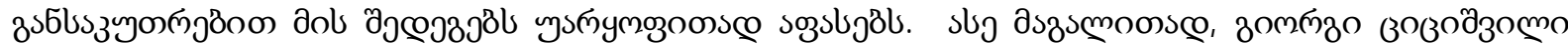

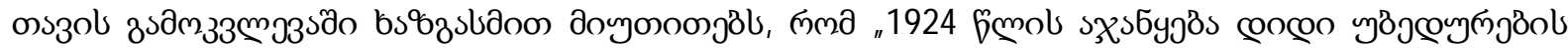

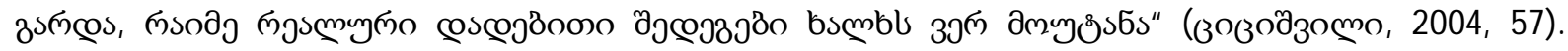

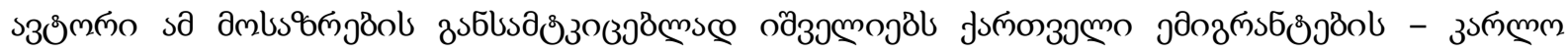

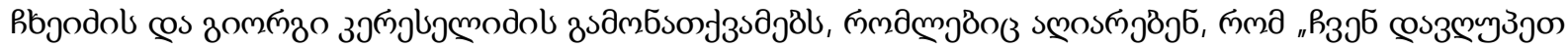




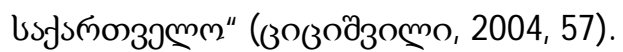

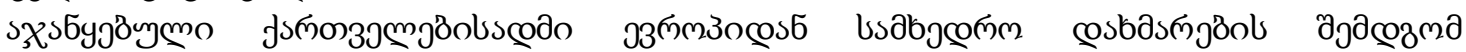

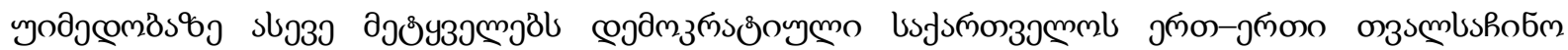

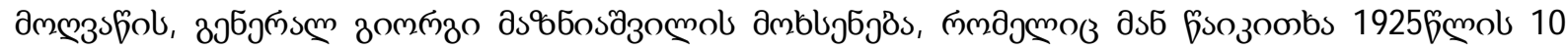

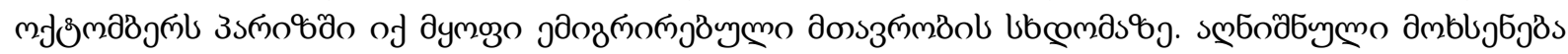

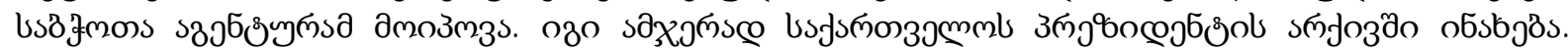

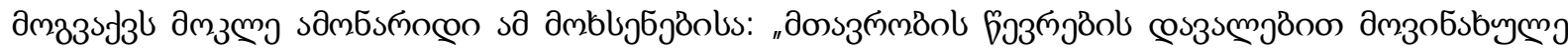

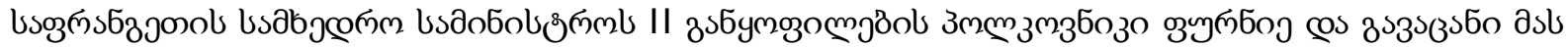

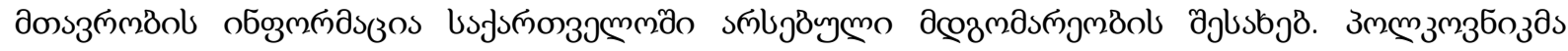

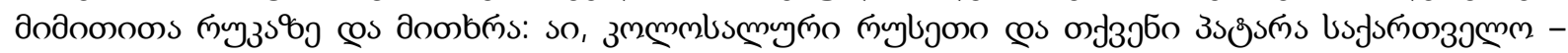

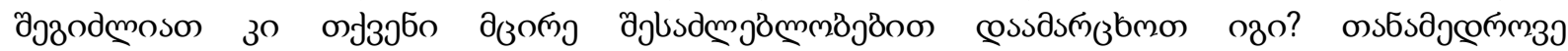

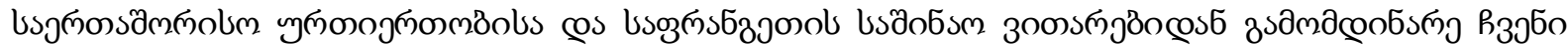

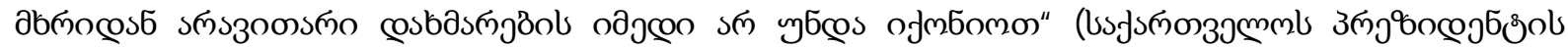
s(njo3o, 14, 2, 28, 652-654).

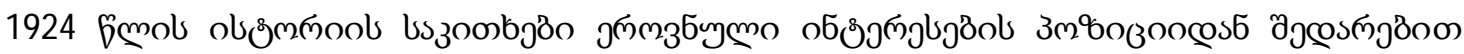

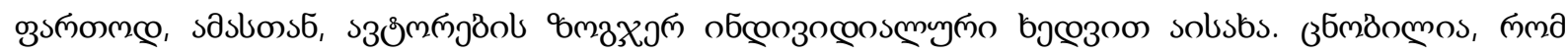

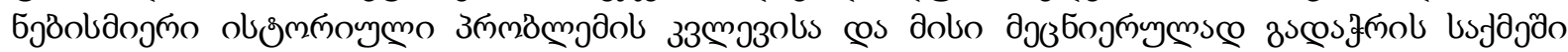

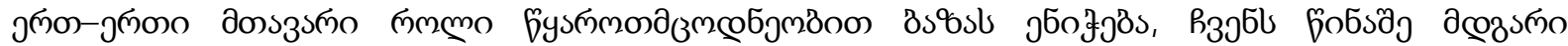

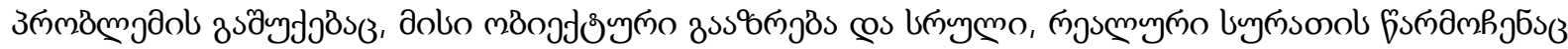

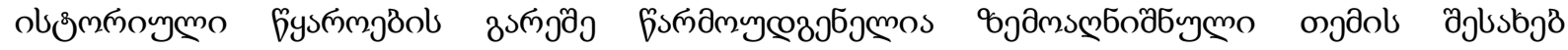

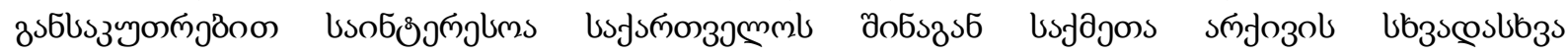

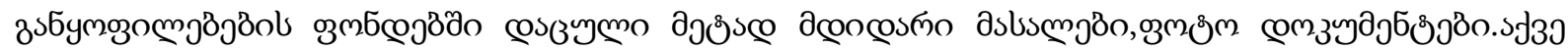

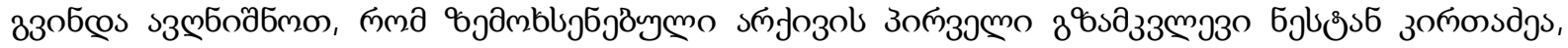

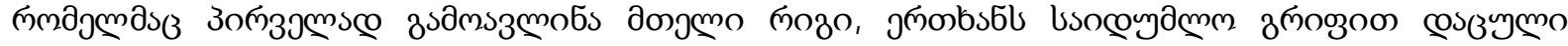

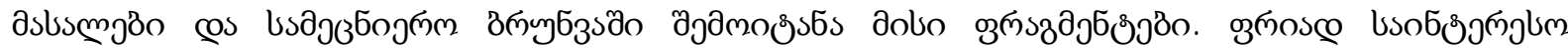

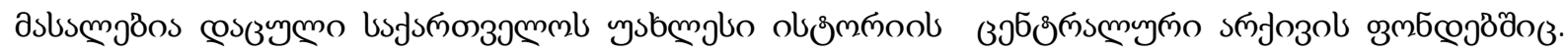

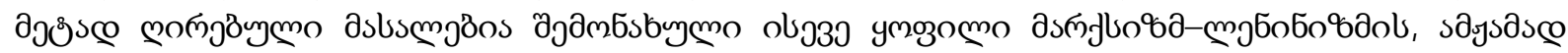

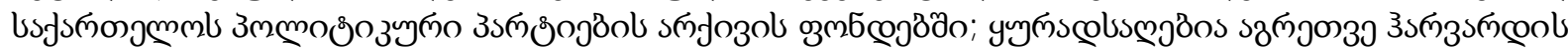

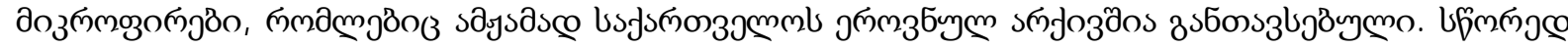

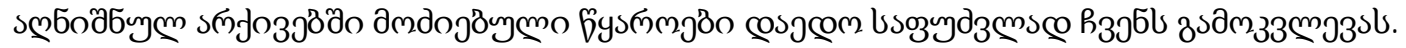

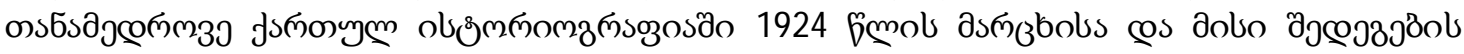

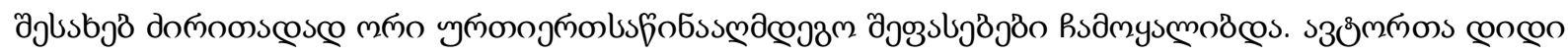

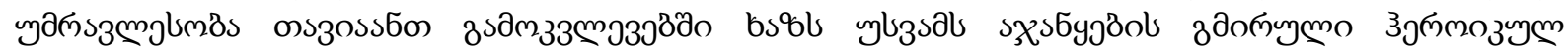

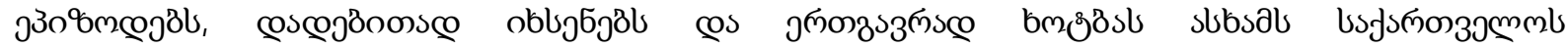

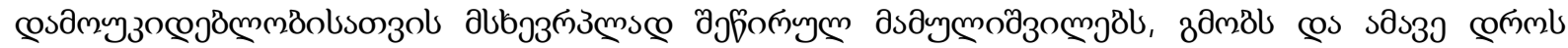

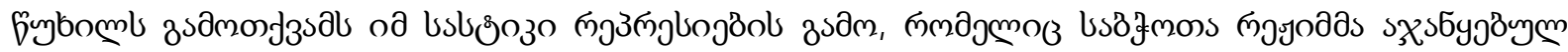

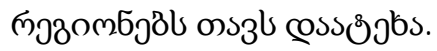

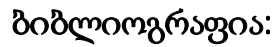

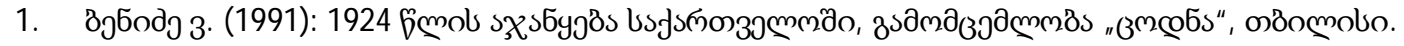

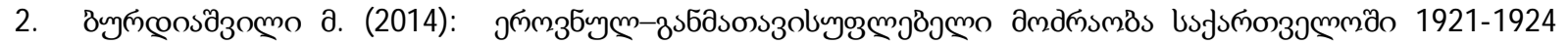

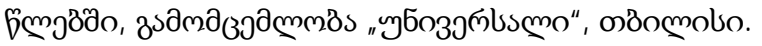

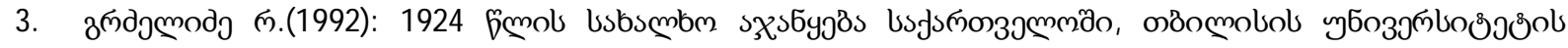

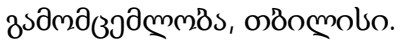

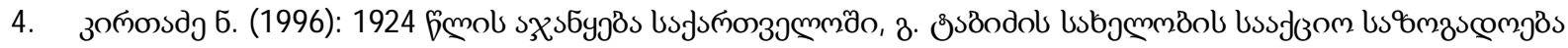

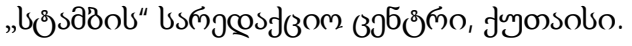

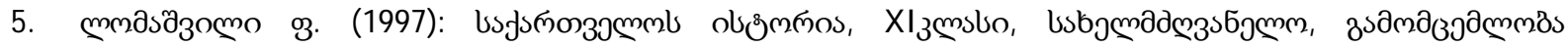

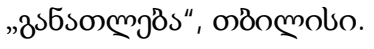




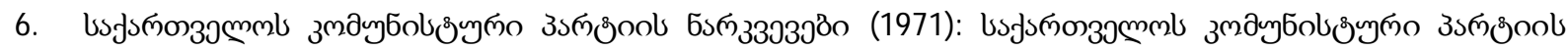

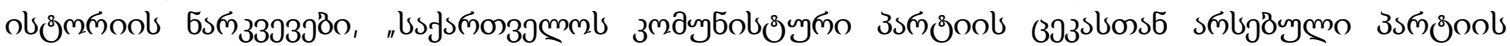

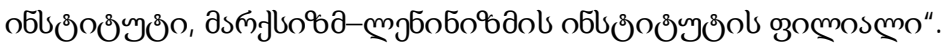

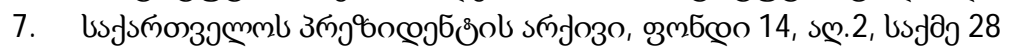

8. Зозоб̆

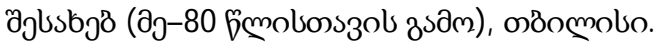

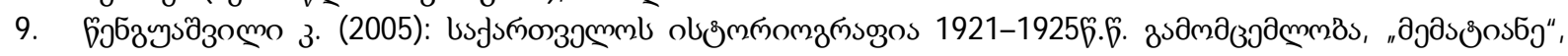
ő̊nmolo.

\title{
How Historians Assess the 1924 Uprising
}

\author{
Kobiashvili Eka \\ Leading Teacher of 6 Public School ,Telavi
}

\begin{abstract}
This article is about 1924 rebellion, which is valued differently by historieans of diferent times.

In modern Georgian historiography, two conflicting assessments have been made about the failure of 1924 and its consequences. The vast majority of the authors emphasize the heroic episodes of the rebellion in their research, positively remembering and praising the patriots who sacrificed their lives for the independence of Georgia, condemning and at the same time expressing their sorrow and grief. The issues of the national struggle against the Soviets, in particular the history of 1924, were reflected relatively broadly from the position of national interests, however, sometimes by the authors from an individual point of view. It is well known that one of the main roles in the study of any historical problem and its scientific solution is based on source science.
\end{abstract}

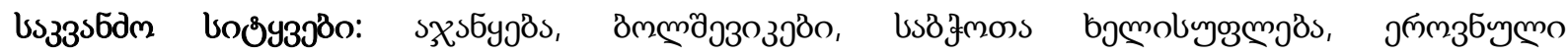

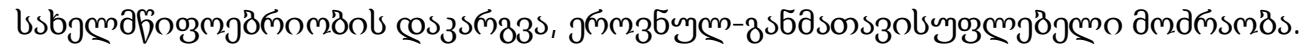

Keywords: Rebellion, the Bolsheviks, Soviet government, loss of national statehood, national liberation movement. 